\title{
FUND MANAGERS ADDING VALUES? MEASURING PERFORMANCE WITHOUT BENCHMARK - A STUDY OF INDIAN MUTUAL FUND SCHEMES
}

\section{KAUSHIK BHATTACHARJEE', DIGANTA MUKHERJEE², MUNAWAR SAYYAD ${ }^{3 *}$}

1. ICFAI Business School, Hyderabad, India

2. Indian Statistical Institute, Kolkata, India

3. ICFAI Business School, Hyderabad, India

* Corresponding Author: Munawar Sayyad, Department of Finance and Accounting, ICFAI Business School, Hyderabad, India, IFHE-IBS Campus, Donthanapally, Shankarapalli Road, Hyderabad, Telangana India 盄+918688484387 $\triangle$ munawar0013@ibsindia.org

\begin{abstract}
This paper calculates the Portfolio Change Measure (PCM) developed by Grinblatt and Titman for a sample of 744 equity schemes of Indian mutual funds over a minimum period of more than two years and less than 11 years. PCM, based on holding of assets, is a measure which is free from 'benchmark' biases arising out of usage of a 'benchmark' portfolio. So, by using PCM as a measure, this paper, without using any benchmark, attempts to assess whether the selected mutual fund managers were able to add value and exhibit superior skills on the average and thus making a case for active fund management over a passive buy and hold strategy. Using the monthly holding statement of each scheme's portfolio, rolling PCM has been calculated monthly with a rolling window of one year. The results of our analysis supported by robustness checks, which include periods of pre-and post-Global Financial Crisis, shows strong evidence of active fund management adding value in the stock selection and hence in return generating process, thus justifying the possession of superior skill or superior information of fund managers at an aggregate level. Finally, using Quantile Regression, we identify some characteristics of the scheme like scheme size and ownership category, which influence PCM significantly.
\end{abstract}

JEL Classification: G14, G23

Keywords: Performance Measurement, Mutual Funds, Benchmark, Holdings

\section{Introduction and Literature Review}

Mutual funds are one of the main pass-through financial instruments through which investors, both retail and institutional; participate in the traded securities market. Though several fund managers follow 'passive' management simply linking the corpus to a particular benchmark index, yet it is also a fact that majority of them claim to add value by managing the portfolios 'actively'. Thus, the longstanding question the academicians, regulators, and investors alike face is whether active fund managers can deliver superior performance, justifying their fees?

Consequently, starting from the sixties, since the development of the Capital Asset Pricing Model (CAPM), the literature on the evaluation of active fund management has grown enormously. Starting from the Treynor ratio (Treynor, 1965), Sharpe ratio (Sharpe, 1966) and Jensen's alpha (Jensen, 1968) up to Fama and French (1993) three-factor model, to which Carhart (1997) added momentum as the fourth factor (known as Carhart's alpha) and more recently 'Information ratio' (Sharpe (2007)) all these measures have looked into 'risk adjusted return' over and above a benchmark portfolio return. In other words, these measures, collectively referred to as 'return based measures' which have 
been developed in the framework of 'risk adjusted return' are essentially a comparison of returns of the concerned portfolio with another portfolio, often referred to as the 'benchmark' portfolio, scaled by some measure of risk. Hence depending upon whether the portfolios chosen are truly comparable (i.e. they are not only based on the same assumptions of risk-return trade-off but also bound by similar constraints); such measures are subject to "benchmark bias" (Roll 1978, Roll 1981). Javier Rodriguez (2018) has used a modified Herfindahl Index to calculate the portfolio diversification in the regional mutual funds for three regions of Asia Pacific, Europe, and Latin America.

So far as benchmarks are concerned, they have to be based on an objective consideration of the needs of the fund manager; otherwise, they are merely arbitrary indicators. ' Roll (1978) has clearly shown that the choice of the benchmark can result in a bias in the estimation of alpha (a)'s. These traditional return-based measures generally result in similar inferences when using the same benchmark, but inferences can vary, even reverse, when using different benchmarks (Grinblatt and Titman 1991, Grinblatt and Titman 1994). As an extension to the existing literature on the selection of benchmarks, Bailey (1992) suggested a set of criteria. However, it is a very rare occasion where a benchmark is readily found satisfying all the criteria. Academic studies ${ }^{2}$ have computed benchmarks based on risk-adjusted native portfolios using an asset pricing model such as CAPM (which is like Jensen's measure, except for the risk-adjusted benchmark). Another major limitation of these traditional return and benchmark-based measures of portfolio performance is that they are indirect measures of skill and performance of a fund manager as they cannot reveal the underlying reasons as to why the portfolio produced the returns it did.

Another strand of relatively recent research has propagated another approach to examine portfolio performance by analysing the holding statement of the funds, i.e. to view investment performance in terms of which securities the manager buys or sells from the portfolio. By examining how the portfolio's holdings change over time, the intelligent investor can establish at a more detailed level which stock or bond positions were responsible for creating that performance. Thus, using a holdingsbased measure can provide additional insights into the qualities of the portfolio manager, like stock picking and timing ability. ${ }^{3}$

Till date the most prominent holding-based measure is the measure proposed by Grinblatt and Titman (1993): The Portfolio Change Measure (henceforth called PCM). ${ }^{4}$ By utilizing the changes in the composition of the portfolio assets over a period of time, PCM eliminates the need to compare the return of a portfolio to a benchmark portfolio and consequently avoids its associated benchmark bias. 5

PCM as a measure of fund returns and fund managers ability to add value was introduced in earlier studies such as by Grinblatt and Titman (1993). It has been used in studies involving Momentum Investment Strategies, Portfolio Performance, and Herding (e.g. Grinblatt et al. (1995), Daniel et al. (1997), Warmers (2000), Chen et al. (2000), and Warmers (2005))

These studies analysed the extent to which mutual funds purchase stocks based on their past returns as well as their tendency to exhibit "herding" behaviour (i.e., buying and selling the same stocks at the same time). On average, using PCM as a measure, it has been found that funds that invested in momentum realized significantly better performance than other funds. Bruce et al. (2014) analysed

\footnotetext{
'Ansella and Molesa (2003).

${ }^{2}$ Grinblatt and Titman (1989, 1994); Grinblatt, Titman and Wermers (1995)

3 For a detailed discussion on how the portfolio holdings data might provide new insights into managed fund performance refer Warmers (2006).

${ }^{4}$ Also known as Average GT measure.

5 By construction it also avoids survivorship bias. However, the main issue with PCM is non-availability of holding data at a higher frequency than month - but it is also a fact that analysis with very high frequency (e.g. daily) or ultra-high frequency (e.g. intra-day) might introduce undesirable noises. (Grinblatt and Titman, 1993)
} 
equity funds using the Carhart Four-factor model by carrying out rolling regression for the Australian market for investigating fund manager performance.

In this paper, we calculate PCM for a sample of 744 Indian mutual fund schemes over a minimum period of 2 years, and a maximum 11 years, with a view of understanding whether at an aggregate level the selected mutual fund schemes can perform over and above a simple buy and hold strategy. India is an important emerging market so far as inflow of funds in the mutual fund industry and hence its importance in the investment scenario of the country is concerned. The Indian mutual fund industry has shown impressive growth in the past two decades both in terms of Asset under Management (AUM) and several folios (i.e. mutual fund accounts). 6 However, in Indian context till date, to the best of our knowledge, no comprehensive long term study has been done to evaluate the efficacy of active management of the schemes (i.e. which tries to evaluate the stock-picking ability by changing portfolio weights of the Indian fund managers) using PCM. Our study fills the gap. Another notable attribute of our paper is adhering to nonparametric methodologies. Due to nonnormality and skewness of the return distributions of various stocks and even return distributions of Net Asset Value (NAV) of different mutual fund schemes. Consequently, even the visual inspection itself (e.g. histogram in Appendix C) for PCM indicates sufficiently that the distribution is too skewed and highly deviates from normality. Since traditional parametric methods of testing hypotheses (i.e. t-test $s$ or ANOVA) which are extremely sensitive to non-normality and skewness, in this paper, we predominantly employ nonparametric techniques (i.e. Quantile Regression, Kruskal-Wallis test, Wilcoxon Signed Rank test etc.) for drawing an inference, so that the issue of biased inference can be mitigated to a large extent.

Primarily, our results, based on substantial analysis of PCM suggest that for equity mutual fund schemes, on the average and in the long run, active fund management by the professional fund managers do add value over and above a simple buy and hold strategy. Additionally, as a part of the robustness check process, we analysed the behaviour of PCM during the Pre, post and in the Global Financial Crisis (GFC). We also show that while management fees do not influence PCM yet, it does get affected by the size of the scheme, AUM of the AMC and several other ownership categories to which a fund belongs.

The remainder of the paper is organized as follows: Section 2 introduces the PCM measure, describes the data, the methodology adopted for (i) calculating the PCM and (ii) drawing the inferences from the results obtained. It also discusses the effect of transaction cost on the behaviour of PCMs. Section 3 presents the result and discusses it along with robustness checks for time periods and ownership structure. Section 4 concludes the paper. It also discusses the limitations and scope of future research.

\section{Methodology and Data}

In this section, we outline the formula for PCM, its estimating methodology and calculation using the data, followed by the formation of Hypothesis. Also, in this section, we establish the irrelevance of management fees and expenses so far, the calculation of PCM is concerned.

\subsection{Statistical background and properties of PCM:7}

Suppose there are $\mathrm{N}$ assets available for a fund manager to invest for a given amount of fund. If the one period expected return on $j$-th asset is $E\left(R_{j}\right)$ and the expected holding of the same asset are

6The industry size almost doubled in the past three years to Rs. 21.8 lakh crore in FY17-18(\$312 bn) from Rs. 10.8 lakh crore (\$166 bn) in FY14-15 and quadrupled in the past 10 years from Rs. 5.1 lakh crore ( $\$ 100$ bn) in FY07-08, as per a white paper from CARE Ratings, Refer to Figure 1.(https://www.moneylife.in/article/equity-mutual-fund-aum-grew-290-percentage-over-the-pastfive-years-report/56261.html

Also refer to Appendix B for a discussion on phases of mutual fund Industry in India

TThis section has been adopted from Grinblatt and Titman (1993) 
denoted by $E\left(W_{j}\right)$. The following sum (SUM) is the sum of differences between the actual expected return of the portfolio managed by the fund manager and the expected return of the same portfolio if returns and weights of all the assets are not correlated.

$$
S U M=\sum_{j}\left[E\left(W_{j} R_{j}\right)-E\left(W_{j}\right) E\left(R_{j}\right)\right]
$$

The same SUM can be looked upon as covariance ${ }^{8}$ between asset return and portfolio weights.

$$
\operatorname{cov}=\sum_{j}\left[E\left(W_{j}-E\left(W_{j}\right)\right) R_{j}\right] .
$$

This covariance is the foundation of PCM and holds at sample covariance level as well, since

$$
\operatorname{Scov}\left(w_{j}, R_{j}\right)=\sum_{t}\left(W_{j t}-\bar{w}_{j}\right)\left(R_{j t}-\bar{R}_{j}\right) / T=\sum_{t}\left(W_{j t}-\bar{w}_{j}\right) \bar{R}_{j t} / T
$$

Where,

Scov $=$ Sample covariance between weights and returns of asset $j$ of period $t$.

$W_{j t}=$ the portfolio weight at the beginning of the portfolio $t$ (with sample mean $\bar{w}_{j}$ )

$R_{j t}=$ the portfolio returns from date $t-1$ tot

$T=$ the number of discrete-time intervals during the period $t$.

Here if it is assumed that period $t+k$ return for each asset is used as a proxy for its expected return during the period $t$ and its period $t-k$ holding as a proxy for its expected holding during period $t$. The PCM can be expressed as follows:

$$
P C M=\sum_{t} \sum_{j}\left[R_{j t}\left(w_{j t}-w_{j t-k}\right)\right] / T
$$

Under the assumption of no superior information available to the fund manager, both the past and current weights should be uncorrelated with current returns. So, over some time PCM should ideally be zero for large samples for any mutual fund scheme. The inner summation is an ex-post estimate of the covariance between returns and weights of the assets in a portfolio at a point in time.

The test employed by Grinblatt and Titman (1993) for testing significance of PCM is a t-test based on the time series of zero-weight portfolio returns, symbolically $t=\sqrt{T}\left(\frac{\overline{P C M}}{S D}\right)$, where $\overline{P C M}$ the sample time series average and SD is the sample time-series standard deviation of the PCM calculated. The justification being, if securities returns are serially uncorrelated, the central limit theorem can be applied, and asymptotic z-tests and chi-square tests are valid for non-normal portfolio returns. These results are valid so far as the returns distributions are not so thick-tailed such that second and higher moments do not exist. However, the existence of such thick tails in financial data is often documented in the empirical finance literature (CLM, 1997 and Ruppert, 2004).

\subsection{Data}

The data contain the monthly security holding statement information for 28 Mutual Fund Houses or Asset Management Companies (AMCs) with more than 1000 open-ended equity schemes since their inception as on March 31. 2016. 'We would like to mention here that the sample thus chosen is free from survivorship bias. However, if the period of existence of any scheme is less than 24 months, we

\footnotetext{
${ }^{8}$ Actual sum of covariance's; however, both weights and returns are unit free quantities and hence the aggregation is valid. 9 It is a random sample out of 44 AMCs existing at that point of time. These AMCs together covers more than $80 \%$ of the AUM of the entire Mutual Fund Industry. Though one of the largest, we have not considered UTI MF because of being outlier in different parameters. Also, the longest holding statement goes back up to January 2005.
} 
have not considered it for analysis, and finally, the number arrived for calculation is 744.10 The schemes are collectively named as 'Equity' schemes as more than $90 \%$ of each scheme invests in pure equity. (Table Al of Appendix-A provides the names of the AMCs). The data has been obtained from NAVINDIA database of CAPITALINE.

\subsection{Calculation of PCM}

For any given scheme from the monthly holding statement, "1 we arrive at monthly GT by using the formula

$G T_{t}=\sum_{j=1}^{N}\left(w_{j t}-w_{j t-1}\right) R_{j t}$ (Taking $\mathrm{k}=1$ in (4), since we have monthly holding data) and next we arrive at yearly $P C M_{T}$ by using the formula $P C M_{T}=\frac{\sum_{t=1}^{T} G T_{t}}{T}$ by taking $\mathrm{T}=12$ and calculate the rolling PCMs by using a rolling window of estimation of 12 months. ${ }^{12}$

\subsection{An Important Property of GT and PCM: Indifference of the Effect of Transaction Cost}

It is a fact that without information about administrative and management fees, it might be challenging to reach any conclusion based on any measure of mutual fund performance. However, in this section, we demonstrate that both GT and PCM are measures which are indifferent to such expenses, in the following manner:

Assuming administrative and management fees (as a proxy by TER, i.e. Total expense ratio ${ }^{13}$ ) for a given scheme remain constant over a given period of time (e.g. a year) the change in the GT measure after accounting for the transaction cost would be given by

$$
G T_{t}^{\tau}=\sum_{j=1}^{N}\left(R_{j t}-\tau\right)\left(w_{j t}-w_{j t-1}\right)
$$

Where $\tau$ is the TER

Now a simple algebra shows that both $G T_{t}^{\tau}$ and $G T_{t}$ would be equal

$$
\begin{array}{r}
G T_{t}^{\tau}=\sum_{j=1}^{N}\left(R_{j t}\right)\left(w_{j t}-w_{j t-1}\right)-\tau \sum_{j=1}^{N}\left(w_{j t}-w_{j t-1}\right) \\
\text { Since, } \because \tau \sum_{j=1}^{N}\left(w_{j t}-w_{j t-1}\right)=0 \forall \mathrm{t} \text { we have } \therefore G T_{t}^{\tau}=\sum_{j=1}^{N}\left(R_{j t}\right)\left(w_{j t}-w_{j t-1}\right)=G T_{t}
\end{array}
$$

\footnotetext{
10Less than 24 months' data was excluded because while calculating the rolling PCM calculations there would be too few observations only to make any valid comparison.

"As per the regulation of SEBI the holdings are to be disclosed on the last working day of any calendar month for each scheme of an AMC/fund house.

12 Hence in this paper PCM stands for PCM 12. Less than 24 months' data was excluded because when taking the rolling data for PCM calculations there would be few observations only.

13 TER is the Total expense ratio calculated based on the recurring expenses of the scheme. The recurring expenses includes investment and advisory fees, marketing and selling expenses, brokerage and transaction cost, audit fees, custodian fees, expenses on fund transfer, expenses charged to a scheme on this basis divided by its net assets give the base total expense ratio TER etc.
} 
I.e. if transaction cost is remaining unchanged over a period, then it does not affect the GT as a measure. In other words, whether the return has been calculated before or after management fees, the conclusion drawn does not alter qualitatively.

So far, the PCM is concerned; the literature is unclear about how to incorporate the transaction cost in the measurement of PCM. (Instead of GT) Assuming it to be deducted just like in the case of Return or Net Asset Value (NAV) we get

$$
\begin{gathered}
G T_{t}^{\tau}=G T_{t}-\tau_{t} \\
P C M^{\tau}=\frac{1}{T} \sum G T_{t}^{\tau}-\frac{1}{T} \sum \tau_{t}=P C M-\bar{\tau}
\end{gathered}
$$

Since empirically $P C M>>\bar{\tau}$ ( Typically for most schemes PCM values are in the range of -450 to 1000 , averaging between $30-50$, whereas $\bar{\tau}$ values are in the range of 0.003 to 0.0268 ). The absolute PCM values are greater than $\bar{\tau}$ values. Hence, we get for all practical purpose $P C M^{\tau}=P C M$. In other words, even if we consider the transaction cost explicitly, it does not alter the results of the ranking or rating exercises of the schemes.

\subsection{Hypothesis}

Given the data and the estimation procedure and statistical properties of PCM, we formulate the following hypotheses:

$H_{01}$. The mean of the rolling PCM is not different from zero.

The rationale behind the above Hypothesis is the fact that under the assumption of no superior information (or stock-picking skill) available to the fund manager, PCM should ideally be zero for large samples.

Hence, if found the contrary it would imply a strong indication of possession of superior information by those professional fund managers. Hence, it would justify the active fund management over simple buy and hold strategy.

\section{Empirical Analysis and Results:}

The test result of the first Hypothesis concerning the mean performance of the rolling PCM has been given in Table 1.

\section{Table 1: Performance of means of rolling PCM (with a rolling window of 12 months)}

\begin{tabular}{cccccccc}
\hline $\begin{array}{c}\text { No. of } \\
\text { schemes }\end{array}$ & Mean & $\begin{array}{c}\text { Standard } \\
\text { error }\end{array}$ & $\begin{array}{c}p \text {-value of } \\
t \text {-statistic }\end{array}$ & $\begin{array}{c}\text { Sign test } \\
\text { statistic }(Z)\end{array}$ & $\begin{array}{c}p \text {-value of } \\
Z\end{array}$ & $\begin{array}{c}\text { Shapiro- } \\
\text { Wilk } \\
\text { statistic }(W)\end{array}$ & $p$-value of $W$ \\
\hline 744 & 34.14 & 3.54 & 0.00 & 309 & 0.00 & 0.47 & 0.00 \\
\hline
\end{tabular}

Source: Authors' Calculation: The table reports the mean value of the PCM of the schemes along with standard error and $\mathrm{p}$ value (probability of a larger value of test statistic under the null Hypothesis) of t-statistic, which is 0.00 suggesting that the PCMs on the average are significantly different from zero. It also gives the Shapiro-Wilk statistic (W) for the sampled firms with p-value (probability of a larger value of test statistic under the null Hypothesis) being zero indicating non-normality of the distribution of the PCMs.

Therefore, we can observe that there is sufficient evidence to doubt the null Hypothesis that the rolling PCMs are not significantly different from zero on the average so far as the monthly returns are concerned. The t-test confirms that. However, given the fact that the departure of the sampling distribution of the mean of the rolling PCM from normality is significant (as implied by the W statistic 
and its $\mathrm{p}$-value); we refer to the nonparametric sign test which also clearly indicates its significant difference from zero.

3.1 Robustness Checks with respect to Median, Subsamples and Winsorizing:

Table 2: Performance of median of rolling PCM (with a rolling window of 12 months)

\begin{tabular}{cccccccc}
\hline $\begin{array}{c}\text { No. of } \\
\text { schemes }\end{array}$ & Median & $\begin{array}{c}\text { Standard } \\
\text { error }\end{array}$ & $\begin{array}{c}\text { p-value of } \\
\text { t-statistic }\end{array}$ & $\begin{array}{c}\text { Sign test } \\
\text { statistic (Z) }\end{array}$ & p-value of $Z$ Shapiro-Wilk & $\begin{array}{c}\text { Statistic (W) } \\
\text { p-value of W }\end{array}$ \\
\hline 744 & 18.23 & 0.88 & 0.00 & 349 & 0.00 & 0.54 & 0.0 \\
\hline
\end{tabular}

Source: Authors' calculation: The table reports the median value of the PCMs of the schemes along with standard error and p-value (probability of a larger value of test statistic under the null Hypothesis) of t-statistic which is 0.00 suggesting that PCMs on the average are significantly different from zero. It also gives the Shapiro-Wilk statistic (W) for the sampled firms. With $p$ value (probability of a larger value of test statistic under the null Hypothesis) being zero indicating non-normality of the distribution of the PCMs.

Since the distribution of the mean of the rolling PCM is non-normal and infested with extreme observations, as a robustness check of our findings, we test the same Hypothesis on the median. ${ }^{14}$ Table 2 displays the result.

Therefore, we can conclude that there is sufficient evidence to doubt the null Hypothesis that the rolling PCMs are significantly different from zero on the average in case of monthly returns. The conclusion is consistent at all the conventional levels of significance as implied by both parametric and nonparametric tests.

Next, as another robustness check, we consider schemes which are in existence for more than 24 months but not more than seven years. This is to exclude any scheme which was in existence during the subprime recession or 'bear phase'. We conduct the same analysis. The results are in Table 3.

Table 3: Performance of means of rolling PCM (with a subsample of schemes in existence up to 7 years)

\begin{tabular}{cccccccc}
\hline $\begin{array}{c}\text { No. of } \\
\text { schemes }\end{array}$ & Mean & $\begin{array}{c}\text { Standard } \\
\text { error }\end{array}$ & $\begin{array}{c}\text { p-value of } \\
\text { t-statistic }\end{array}$ & $\begin{array}{c}\text { Sign test } \\
\text { statistic (Z) }\end{array}$ & $\begin{array}{c}\text { p-value of } \\
\mathbf{Z}\end{array}$ & $\begin{array}{c}\text { Shapiro-Wilk } \\
\text { statistic (W) }\end{array}$ & p-value of W \\
\hline 416 & 30.55 & 5.34 & 0.00 & 167 & 0.00 & 0.46 & 0.00 \\
\hline
\end{tabular}

Source: Authors' Calculation: The table reports the median value of the PCMS of the schemes along with Standard error and p-value (probability of a larger value of test statistic under the null Hypothesis) of t-statistic which is 0.00 suggesting that PCMs on the average are significantly different from zero It also gives the Shapiro-Wilk statistic (W) for the sampled firms. With p-value (probability of a larger value of test statistic under the null Hypothesis) being zero indicating non-normality of the distribution of the PCMs.

In this case, as well we can observe that there is enough evidence to doubt the null Hypothesis that the rolling PCMs are not significantly different from zero on the average so far as the monthly values are concerned. Firstly, the t-test confirms that. However, given the fact that the departure of the sampling distribution of the mean of rolling PCM from normality is significant (as implied by the W statistic and its $p$-value); we refer to the nonparametric sign test which also clearly indicates its significant difference from zero.

\footnotetext{
${ }^{14}$ Hypothesis $\mathrm{H}_{01 \mathrm{~A}}$ : The median of the rolling PCM is not significantly different from zero.
} 
Table 4: Performance of means of rolling PCM (Winsorized)

\begin{tabular}{ccccccc}
$\begin{array}{c}\text { Percent } \\
\text { Winsorized }\end{array}$ & Mean & Standard error & $\begin{array}{c}\text { LCL(Lwer } \\
\text { Confidence } \\
\text { Limit) }\end{array}$ & $\begin{array}{c}\text { UCL(Upper } \\
\text { Confidence } \\
\text { Limit) }\end{array}$ & t-stat & p-value \\
\hline $5 \%$ & 25.26 & 1.86 & 21.59 & 28.93 & 13.53 & 0.00 \\
$10 \%$ & 25.14 & 1.03 & 23.11 & 27.17 & 24.37 & 0.00 \\
\hline
\end{tabular}

Source: Authors' Calculation: The table reports the median value of the Schemes along with Standard error and p-value (probability of a larger value of test statistic under the null Hypothesis) of t-statistic which is 0.00 suggests that PCMs on the average are significantly different from zero. It also gives the Shapiro-Wilk statistic (W) for the sampled firms. With p-value (probability of a larger value of test statistic under the null Hypothesis) being zero indicating non-normality of the distribution of the PCMs. The sample consists of Winsorized extremes at $5 \%$ and $10 \%$ levels.

Next, we winsorized the extreme upper $5 \%$ and $10 \%$ values and then repeated the analysis. The results are in Table 4. It can be observed that even after Winsorizing, we get similar results that are supporting the original conclusion.

\subsection{Effect of Market Conditions on GT (and PCM)}

Since our data set spans several years (2016 to 2005) for many a scheme, it becomes imperative to test for different market conditions as an influencing factor affecting the overall performance of PCM, especially controlling for bearish and bullish phases. The most prominent macroeconomic event affecting the equity markets all over the worlds during this period is undoubtedly "Global Financial Crisis" (GFC). Thus, we proceed to test if the performances of the fund managers, as indicated by the PCMs, are contingent upon market conditions as implied by the GFC. Following, Ben-David et al. (2012), we define "Before Crisis", "After Crisis", and "During Crisis" as up to November 2007, December 2007 to June2010 and after June 2010, respectively. This is also the reason we identify and segregate schemes that were 'live' spanning all the three-time periods. ${ }^{15}$ In this case, also we find that both parametric and nonparametric tests are indicating that under all the three market conditions, the PCM is significantly different from zero.

Table 5: Comparison of Mean \&Median of Rolling PCM Pre, Post \& During Global Financial Crisis

\begin{tabular}{llllll}
\hline Period & Test & Median & Mean & Test Stat Value & p-value \\
\hline Crisis & Sign (M) & 12.86 & & 1246 & $<0.0001$ \\
Crisis & Signed Rank (S) & 12.86 & & 1651174 & $<0.0001$ \\
Crisis & t-test & & 30.75 & 11.79 & $<0.0001$ \\
Before Crisis & Sign (M) & 8.92 & & 1359 & $<0.0001$ \\
Before Crisis & Signed Rank (S) & 8.92 & & 2036068 & $<0.0001$ \\
Before Crisis & t-test & & 44.29 & 2.91 & 0.0037 \\
After Crisis & Sign (M) & 5.75 & & 4624 & $<0.0001$ \\
After Crisis & Signed Rank (S) & 5.75 & & 24564092 & $<0.0001$ \\
After Crisis & t-test & & 34.50 & 8.16 & $<0.0001$ \\
\hline
\end{tabular}

Source: Authors' Calculation: The table reports the median and the mean values of the combined schemes after being segregated based on pre, post and during the crisis periods. The table shows, along with test statistic the corresponding $p$ values which are much lower than 0.01 suggesting that PCMs on the average are significantly different from zero during all the three sub-periods that is the pre, post and in the crisis periods.

Indeed, the next stage of analysis should find whether the PCM on the average were significantly different from each other. To answer that we employ the Kruskal Wallis Test (KW), which can be looked upon as the nonparametric counterpart of one-way Anoval' ${ }^{16}$. Results of KW test indicate

\footnotetext{
15 The number of AMCs boils down to 11 and the number of schemes boils down to 157.

16Because of non-normality and highly skewed distribution we do not perform one-way ANOVA parametric testing as the underlying assumptions for the parametric ANOVA would be violated
} 
that there are significant differences between PCMs at the mean level: during the crisis period, it is least, followed by after crisis period and highest being before the crisis period started. It supports the conjecture that at a collective level, information asymmetry or superior stock-picking skill is lowest across the fund managers during that crisis period.

\section{Table 6: Kruskal- Wallis Test for testing}

\section{Chi-Square}

562.97

2

DF $<0.0001$

$<0.0001$

Source: Authors' Calculation: The table reports the Kruskal Wallis test. The value of the test statistic is 562.97, which follows a Chi-Square distribution with 2 degrees of freedom (since there are three levels). The p-value (probability of a larger statistic under the null Hypothesis) is $<0.001$. This leads to the rejection of the null Hypothesis that there is a difference in location parameter for PCM among the different market conditions, i.e. pre, post and during the GFC.

\subsection{Comparison of active funds with Index funds}

Next, we proceed to test if the means of the rolling PCM is different from zero significantly since the portfolio of Index funds also change weights from time to time due to change in the market capitalization of the constituent stocks. We calculated PCM for Index funds ${ }^{17}$, the number being 52 for the study period by considering quarterly time intervals ${ }^{18}$ instead of monthly. Next, we test the same against Ho (The mean of the rolling PCM is not different from zero), and we find that $\mathrm{HO}$ is being rejected (at $1 \%$ level) by both parametric and nonparametric tests.

\section{Table 7: Performance of means of rolling PCM of Index funds}

\begin{tabular}{cccccccc}
$\begin{array}{c}\text { No. of } \\
\text { schemes }\end{array}$ & Mean & $\begin{array}{c}\text { Standard } \\
\text { error }\end{array}$ & $\begin{array}{c}\text { p-value of } t- \\
\text { statistic }\end{array}$ & $\begin{array}{c}\text { Sign test } \\
\text { statistic (Z) }\end{array}$ & $\begin{array}{c}\text { p-value of Z } \\
\text { shapiro-Wilk } \\
\text { statistic (W) }\end{array}$ & p-value of W \\
\hline 52 & 0.682 & 0.068 & 0.000 & 282 & 0.00 & 0.59 & 0.00 \\
\hline
\end{tabular}

Source: Authors' Calculation: The table reports the mean value of the PCM of the schemes along with standard error and pvalue (probability of a larger value of test statistic under the null Hypothesis) of t-statistic, which is 0.00 suggesting that the PCMs on the average are not significantly different from zero. It also gives the Shapiro-Wilk statistic (W) for the sampled firms with p-value (probability of a larger value of test statistic under the null Hypothesis) being zero indicating non-normality of the distribution of the PCMs.

Apparently, this result seems to be counterintuitive at first glance and thus not supporting the basic premise of Grinblatt\& Titman (1993) that for a passive 'buy and hold' fund, the PCM should be ideally zero and $\mathrm{H}_{\mathrm{o}}$ should ideally not be rejected at a given significance level. However, according to our observations, it is not so. This is because that while analysing the holdings of index funds, we find that the portfolio of these schemes changes the weights based on the change in the performance of constituent stocks in the index. In fact, the weights do change on a monthly as well as a quarterly basis for most of the stocks. This change in weights (compelled by the change of weights of stocks in the index due to their performance change) makes the index funds not passive 'buy and hold' funds in true sense. Over and above, many of the index funds do not mimic the index cent-percent. We find, about $80 \%$ of the funds shadow the index only to the extent of 85-90 percent (e.g. it is natural to observe that an indexing scheme following Nifty 50 index has 40-45 stocks of Nifty index in its portfolio). Hence the effect of change of weights of stock in the composition of the index is often influencing

17It would have ideal to consider the same for ETFs too. However, ETFs gained popularity in India in recent past especially from 2015 onwards. For our sample period the number of ETFs having enough historical data points is very less compared to other funds and hence we did not cover the ETFs in our study. Further studies may be conducted with respect to ETFs and its influence towards Indian Mutual fund industry.

${ }^{18}$ Assuming that quarterly changes would be more prominent and higher in magnitude. 
in an out of proportion magnitude in the PCM of the Index fund. However, even with significant positive PCM, these index funds scores much less when compared to their actively managed counterparts. In other words, we find that on the average the PCM of these index funds $(0.68)$ is much less than the average PCM of the actively managed funds (34.14)

In the following table, we report the test of equality of mean PCM of Index funds vs the same for the Active funds

Table 8: Equality of Mean PCM of Index funds vs Active funds

\begin{tabular}{lccc}
\hline Method & Variance & t_value & p_value \\
\hline Pooled & Equal & 6.81 & $<0.001$ \\
Satterwhaite & Unequal & 29.15 & $<0.001$ \\
\hline
\end{tabular}

From the above table, we observe that the null of equality of means is being rejected under both equal and unequal variance with levels much less than 0.01 . Hence, in summary, we may conclude that though the rolling PCM of index funds are not quietly significantly different from zero, it is much less than their actively managed counterpart. This corroborates the basic premise of Grinblatt\& Titman (1993) that active fund managers should ideally add more value to through their stock-picking skills than passive fund managers who simply mimic the index.

\subsection{Transaction Costs}

In section 2.3 of the paper, we have demonstrated that GT is indifferent of transaction cost if the transaction cost is unchanged over a period. We have also shown that PCM as a measure also remain unaffected even when it is changing over time provided the average transaction cost is small enough. However, if we consider the transaction cost is also changing over time, i.e. $\tau$ (Tau) is not fixed rather changes with changes in the period, it is not possible to show mathematically (and hence the need for empirical validation) that GT is independent of the transaction cost. In such a case at best, we may investigate the effect of changing transaction cost empirically using actual values. We first find the change of the transaction cost (as measured by Total expense ratio (TER)) on a monthly as well as every quarter. Next with this transaction cost data, we recalculate the PCM for a sample of 153 diversified equity schemes which were actively managed. We observe that monthly the change of the expense ratio of those selected schemes is less than 0.02 percent on the average. Even if we consider the quarter on quarter change in expense ratio, there is not much increase with average being 0.038 per cent. As a result, we find that the decrease in the value of PCM is only $1.76 \%$ on the average. Needless to mention that statistically to the resultant PCM is significantly greater than zero.

Here we would like to reiterate that literature on the effect of transaction cost is not unanimous on its effect on the mutual fund performance. Though it is usually considered that after accounting for transaction cost the performance of mutual funds loses its sheen, there are several earlier studies which have shown that transaction cost does not affect the performance of the mutual fund to a great extent. Wermers (2002) suggested that the transaction costs affect $1.6 \%$ for mutual fund performance. In the European context, Bams and Otten (2002) also suggest that active managers tend to outperform market despite transaction costs. Several other studies, like Chen et al. (2004), Ferreira et al. (2013) demonstrated no significant impact of transaction cost on fund performance. However, in this paper, we are examining to what extent PCM, as a measure of value addition through changes in the portfolio weights gets affected by transaction cost. Overall, our findings suggest that the effect of transaction cost is not significant. 
Table 9: Performance of means of rolling PCM with transaction cost (with a rolling window of 4 quarters)

\begin{tabular}{cccccccc}
\hline $\begin{array}{c}\text { No. of } \\
\text { schemes }\end{array}$ & Mean & $\begin{array}{c}\text { Standard } \\
\text { error }\end{array}$ & $\begin{array}{c}\text { p-value of } t- \\
\text { statistic }\end{array}$ & $\begin{array}{c}\text { Sign test } \\
\text { statistic (Z) }\end{array}$ & p-value of Z & $\begin{array}{c}\text { Shapiro-Wilk } \\
\text { statistic (W) }\end{array}$ & $\begin{array}{c}\text { p-value of } \\
\text { W }\end{array}$ \\
\hline 153 & 33.53 & 3.248 & 0.000 & 277 & 0.00 & 0.66 & 0.00
\end{tabular}

Source: Authors' Calculation: The table reports the mean value of the PCM of the schemes along with standard error and $p$ value (probability of a larger value of test statistic under the null Hypothesis) of t-statistic, which is 0.00 suggesting that the PCMs on the average are not significantly different from zero. It also gives the Shapiro-Wilk statistic (W) for the sampled firms with p-value (probability of a larger value of test statistic under the null Hypothesis) being zero indicating non-normality of the distribution of the PCMs.

\subsection{Effect of Large Cap, Mid-Cap and Small-Cap funds}

As per the sample data which we have considered in our analysis evidence that categorization, such as large-cap, mid-cap and Small-cap (though the classification itself is somewhat arbitrary) does affect the PCM values, in order to investigate this effect of classification we first define (as there was no standard definition in the Indian context before 2018) large-cap funds as schemes, which at any given point in time, invested more than $50 \%$ of its corpus (or AUM) in stocks of companies which fall into the categories of large market cap stocks (approximately top 10\% of the universe of stocks).

\section{Table 10: Performance of means of rolling PCM with transaction cost (with a rolling window} of 12 months)

\begin{tabular}{ccccccccc}
\hline $\begin{array}{c}\text { Type. of } \\
\text { schemes }\end{array}$ & $\begin{array}{c}\text { No. of } \\
\text { schemes }\end{array}$ & Mean & $\begin{array}{c}\text { Standard } \\
\text { error }\end{array}$ & $\begin{array}{c}\text { p-value of } \\
\text { t-statistic }\end{array}$ & $\begin{array}{c}\text { Signtest } \\
\text { statistic (Z) }\end{array}$ & $\begin{array}{c}\text { p-value of } \\
\mathbf{Z}\end{array}$ & $\begin{array}{c}\text { Shapiro- } \\
\text { Wilk } \\
\text { statistic } \\
\text { (W) }\end{array}$ & $\begin{array}{c}\text { p-value of } \\
\text { W }\end{array}$ \\
\hline Large & 416 & 43.95 & 2.67 & 0.00 & 99 & 0.00 & 0.51 & 0.00 \\
\hline Mid & 97 & 35.82 & 3.12 & 0.00 & 29 & 0.00 & 0.51 & 0.00 \\
\hline Small & 62 & 13.81 & 3.42 & 0.00 & 26 & 0.00 & 0.82 & 0.00 \\
\hline MultiCap & 169 & 16.47 & 2.19 & 0.00 & 27 & 0.00 & 0.79 & 0.00 \\
\hline
\end{tabular}

Source: Authors' Calculation: The table reports the mean value of the PCM of the schemes along with standard error and $p$ value (probability of a larger value of test statistic under the null Hypothesis) of t-statistic, which is 0.00 suggesting that the PCMs on the average are not significantly different from zero. It also gives the Shapiro-Wilk statistic (W) for the sampled firms with p-value (probability of a larger value of test statistic under the null Hypothesis) being zero indicating non-normality of the distribution of the PCMs.

Next, we define mid-cap funds as schemes, which at any given point in time, invested more than $50 \%$ of its corpus( or AUM) in stocks of companies which fall into the categories of mid-marketcapitalization stocks(approximately between top $10 \%$ to top $50 \%$ of the universe of stocks) and finally, we define small-cap funds as schemes, which at any given point in time, invested more than $50 \%$ of its corpus ( or AUM) in stocks of companies which fall into the categories of small-marketcapitalization stocks(approximately between below top 50\% of the universe of stocks). Otherwise, we considered a fund as hybrid or multi-cap as mentioned earlier that we started with 744 diversified equity funds and according to this categorization, the percentage of such firms were $56 \%$ Large Cap, 23\% multi-cap, $13 \%$ Mid Cap and $8 \%$ in Small Cap. The PCM values for Large Cap and mid-cap were 38.95 and 35.82, respectively whereas the same for multi-cap and small-cap were 15.6 and 13.81 respectively. We find that these mean PCMs are all significantly different from zero, and also, they are statistically significantly different from each other. Thus, our preliminary analysis (as presented in 
Table 10) suggests that managers managing large-cap and mid-cap funds have better stock-picking ability than multi-cap and small-cap funds. ${ }^{19}$

\subsection{Effect of Different Mutual Fund Size and Ownership Categories}

Given the structure of the Indian Mutual Fund Industry (See Appendix D) it also becomes imperative to test whether the size of the scheme, size of the Fund House (or AMC) or the ownership structure of the AMC have any bearing on the PCM. Similarly, as we have done for Market Conditions, we have tested whether on the average PCM is significantly different from zero for Large Cap, Mid Cap, and small-cap funds. In all the cases mentioned above, we find that the PCM on the average is significantly greater than zero. Therefore, instead of repeating the same type of analysis further what we do next is to try to find out if there exists any significant relationship for a scheme's PCM and its other characteristics like NavSize, AMCSize and Ownership structure.

Hence, we ran Quantile regression 20 of PCM (dependent variable) on NavSize, AMCSize, Category and Type as the independent variables.

$$
P C M=\alpha+\beta_{1} \text { NAVSize }+\sum_{i=1}^{2} \beta_{3 i} \text { Type }_{i}+\sum_{i=1}^{4} \beta_{4 i} \text { Category }_{i}+\beta_{2} \text { AMCSize }+\varepsilon
$$

Here NavSize (Total NAV of the scheme) and AMCSize (a proxy for AUM) are continuous variables whereas rest of the variables are categorical. Since this is a cross-sectional regression, we have taken the monthly average of 2015-16 for all the continuous variables. The variable 'Type' has three levels, i.e. Private, Bank Sponsored and Institution sponsored, and the variable 'Category' has five levels viz. Foreign, Indian, Joint venture predominantly Indian, Joint Venture Predominantly Foreign and Others.

The choice of Quantile regression (introduced by Koenker and Bassett (1978)) over OLS regression in our case is natural and logical since the unconditional distribution of PCM is characterized by nonnormality and skewness (appendix C): Quantile regression, which includes median regression as a particular case, provides a complete picture of the effect of the independent variables when a set of percentiles is modelled. Thus, it can capture important features of the data that might be omitted by models that average over the conditional distribution. As quantile regression makes minimal distributional assumption concerning the error term, it offers substantial model robustness. Quantile regression is flexible because it does not involve a link function that relates the variance and the mean of the response variable. Quantile regression also offers robustness concerning outliers in data. Unlike OLS regression, quantile regression is robust to extreme values in the response direction.

Table 11: Model information and Summary Statistics

\begin{tabular}{lcccccc}
\hline Variable* & Q1 & Q2 & Q3 & Mean & S.D. & MAD \\
\hline NavSize & 68.14 & 263.6 & 952.0 & 944.6 & 1841.9 & 351.7 \\
AMCSize & 8043.3 & 52283.8 & 159369 & 76929.8 & 70115.3 & 75028.6 \\
\hline No. of Independent Variables & \multicolumn{5}{c}{$2+8$ dummy variables for category and type } \\
Optimization Algorithm & \multicolumn{5}{c}{ Simplex } \\
Methods for confidence limits & \multicolumn{5}{c}{ Resampling } \\
\hline
\end{tabular}

Both the variables are in Rs. Crore. 1 Crore=10 Million. IUSD=Rs.70 (approx.)

\footnotetext{
19This is an interesting finding which could have been taken up for future exploration.

20 We ran both OLS regression with White's heteroscedasticity corrected covariance estimators as well as Quantile regression. Interestingly both are qualitatively similar. However, here we present the results of Quantile regression at the quantile level 10\%, 50\% and $90 \%$ to get a comprehensive idea.
} 
By examining all the three regressions, we find that size of the schemes (as represented by NavSize) have a positive influence on PCM. The same cannot be said for AMCSize, which implies it is the scheme that is more important in the performance that the brand or size of the AMC to which it belongs. Foreign, bank-sponsored, and institutional ownership categories create more variability in the distribution of PCM values (lower quantile dummy has a negative coefficient, whereas higher quantile dummy has a positive coefficient). The reverse is seen in case of ownership category of a joint venture (predominantly foreign). This implies that the PCM data is heterogeneous in terms of its determinants or covariates so far ownership and size are concerned. This asymmetric response of PCM owing to its covariate's heterogeneity needs to be further investigated.

\section{Table 12: Parameter Estimates of the Quantile Regression-10\% Quantile}

\begin{tabular}{lccc}
\hline Parameter & Estimate & SE & P-Value \\
\hline Intercept & 55.72 & 14.45 & $<0.0001$ \\
NavSize & 0.0281 & 0.0061 & $<0.0001$ \\
AMCSize & 0.0001 & 0.0009 & 0.0837 \\
Category_Foreign & -45.159 & 15.0 & 0.0027 \\
Category_Indian & -29.45 & 13.64 & 0.0310 \\
Category_Joint venture predominantly Foreign & 71.27 & 19.70 & 0.0003 \\
Category_Joint venture predominantly Indian & -3.2727 & 11.86 & 0.7826 \\
Type_BankSponsored & -44.80 & 6.07 & $<0.0001$ \\
Type_Institution & -48.96 & 6.94 & $<0.0001$ \\
\hline
\end{tabular}

Description: Observations at 10\% quantile level Regression output: 1) Intercept is significant and positive at 1\% level 2) NavSize is significant and positive 3) AMCSize is significant and positive at $10 \%$ level 4) Type Dummies are significant at 1\% level 5) All Category dummies are significant except Category_Joint venture predominantly Indian with Category_Joint venture predominantly Foreign dummy having the maximum impact of magnitude.

Table 13: Parameter Estimates of the Quantile Regression-50\% Quantile (Median)

\begin{tabular}{lccc}
\hline Parameter & Estimate & SE & P-Value \\
\hline Intercept & -5.49 & 0.83 & $<0.0001$ \\
NavSize & 0.0003 & 0.0002 & 0.0836 \\
AMCSize & 0.00001 & 0.0001 & 0.0015 \\
Category_Foreign & 8.79 & 0.9514 & $<0.0001$ \\
Category_Indian & 11.69 & 0.9298 & $<0.0001$ \\
Category_Joint venture predominantly Foreign & 15.15 & 1.0064 & $<0.0001$ \\
Category_Joint venture predominantly Indian & 7.69 & 0.7659 & $<0.0001$ \\
Type_BankSponsored & 5.64 & 0.4993 & $<0.0001$ \\
Type_Institution & 1.22 & 0.6265 & 0.0515 \\
\hline
\end{tabular}

Description: Observations at Median level Regression output: 1) Intercept is significant and negative 2) NavSize is significant at $10 \%$ level 3) AMCSize is significant at $1 \%$ level 4) All Ownership category dummies are significant at 1\% level. 5) Type_BankSponsored is significant at $1 \%$ level whereas Type_Institution is significant at $10 \%$ level. 
Table 14: Parameter Estimates of the Quantile Regression-90\% Quantile

\begin{tabular}{lccc}
\hline Parameter & Estimate & SE & P-Value \\
\hline Intercept & -13.62 & 4.27 & 0.0015 \\
NavSize & 0.0003 & 0.0001 & $<0.0001$ \\
AMCSize & 0.0001 & 0.00001 & $<0.0001$ \\
Category_Foreign & 4.30 & 3.77 & 0.2546 \\
Category_Indian & -5.58 & 3.88 & 0.1515 \\
Category_Joint venture predominantly Foreign & -6.68 & 7.91 & 0.3991 \\
Category_Joint venture predominantly Indian & -9.7721 & 3.53 & 0.0059 \\
Type_BankSponsored & 10.05 & 3.08 & 0.0012 \\
Type_Institution & 22.24 & 1.53 & $<0.0001$ \\
\hline
\end{tabular}

Description: Observations at 90\% quantile level Regression output: 1) Intercept is significant and negative 2) NavSize is significant at $1 \%$ level 3) AMCSize is significant at $1 \%$ level 4) Only category dummy Joint Venture predominantly Indian significant at 1\% level. 5) Type_BankSponsored and Type_Institution are significant at 1\% level with Type Institution having more variability.

Table 15: Goodness of Fit (GOF) Statistics

\begin{tabular}{lcc}
\hline GOF Measure & Quantile & Value \\
\hline R1 & 10 & 0.55 \\
R1 & 50 & 0.57 \\
R1 & 90 & 0.63 \\
\hline Table 15 shows the Goodness of Fit Statistics for all the three quantiles, and for all the three cases we find the fit is satisfactory ${ }^{21}$
\end{tabular}

\section{Conclusion}

Measurement of mutual fund portfolio performance and hence the performances of the fund managers is a long-standing area of interest for both academic as well as managerial practice point of view. Since the traditional returns-based measures of judging portfolio performance suffer from a severe 'benchmark bias', we have made use of PCM measure, which is free from such bias, on several Indian equity mutual fund schemes. The results obtained are commensurate with the original findings of Grinblatt and Titman (1993) what they obtained on mutual fund schemes using quarterly holding data. Thus, we may conclude by saying that there are positive signals of information asymmetry in the Indian market with mutual fund managers having superior information about the performance of stocks as a whole and that gets reflected in the adjustment of portfolio weights, making the PCMs significantly greater than zero on the average. This broad conclusion holds even when we divide the time horizon into pre, post and during the global financial crisis or when we

${ }^{21}$ It is to be noted that the underlying rationale of calculating Goodness of Fit in a quantile regression is very different from the ones employed in OLS or GLM regressions. For instance, the most popular coefficients of determination i.e. R-square is not applicable in the quantile regression anymore. Instead, a statistic called "Rl" should be used which is estimated as 1 minus the ratio between the sum of absolute deviations in the fully parameterized models and the sum of absolute deviations in the null (non-conditional) quantile model. The values are useful for comparisons between quantile models, but they are not comparable to standard coefficients of determination. The latter is based on the variance of squared deviations, whereas goodness of fit values for quantile regression is based on absolute deviations. 
classify the schemes based on market capitalization, Size of Total NAV, Size of the AMC and Ownership structure, albeit at varying degrees. Thus, we have found empirical support of the fact that at a collective level, either information asymmetry or superior stock-picking skill was lowest during that crisis period implying the conjecture of lower level of information flow across markets, adversely affecting the liquidity. We also find that transaction costs that are existing in the market do not affect the PCM significantly as a measure of a fund manager's ability to add value. Also, when compared with the PCM of index funds, we find that actively managed funds are adding values through their adjustments of portfolio weights. So far as the managerial implication is concerned, there is substantial evidence that fund managers having superior information plays a vital role in deciding the directions of the markets and managers with superior information and skills (as indicated by higher PCM) can perform better during 'bad', 'bearish' or 'recession' period. There are, however, two caveats attached to these conclusions; firstly, though PCM as a measure is unaffected by the level of Transaction cost, yet to what extent this significant positive PCM could prove to be profitable, i.e. fund managers can deliver an above-average return, especially after accounting for the expenses that cannot be ascertained. This is because PCM by construction is not a measure of profitability per se. Secondly, in order to identify which are the specific actions that made the PCMs significantly higher than zero; further detailed studies looking into the attribution analysis of PCMs are required.

\section{References}

Ansella, J., Molesa, P. and Smart, A. (2003). 'Does benchmarking help?' International Transactions in Operational Research, Vol. 10, pp. 339-350.

Bailey, Jeffrey V. (1992). 'Are Manager Universes Acceptable Performance Benchmarks?' Journal of Portfolio Management, Vol. 8, pp. 9-13.

Carhart, M (1997). 'On Persistence of Mutual Fund Performance.', Journal of Finance, Vol. 52, pp.57-82

[CLM] John Y. Campbell, and Andrew W. Lo, and A. Craig MacKinlay. (1997). 'The Econometrics of Financial Markets', Princeton University Press.

Kent Daniel, Mark Grinblatt, Sheridan Titman and Russ Wermers (2012). 'Measuring Mutual Fund Performance with Characteristic-Based Benchmarks'

Marcin Kacperczyk, Clemens Sialm and Lu Zheng, (2005). 'On the Industry Concentration of Actively Managed Equity Mutual Funds'

Robert Kosowski, Allan Timmermann, Russ Wermers and Hal White, (2007). 'Can Mutual Fund "Stars" Really Pick Stocks? New Evidence from a Bootstrap Analysis'

Fama E., and French K. (1993). 'Common Risk Factors of Stocks and Bonds', Journal of Financial Economics, Vol. 33, pp.3-56

Grinblatt, Mark and Titman, Sheridan. (1991) 'Do Benchmarks Matter? Do Measures Matter? A Study of Monthly Mutual Fund Returns', University of California, Los Angeles.

Grinblatt, M and Titman, S. (1989). 'Mutual Fund Performance: An Analysis of Quarterly Portfolio Holding', Journal of Business, Vol. 62, pp.393-416

Grinblatt M and Titman, S (1993). 'Performance Measurement without Benchmark: An Examination of Mutual Fund Returns', Journal of Business, Vol. 66, pp.47-68

Grinblatt Mark; Titman Sheridan. (1989). 'The Relation between Mean Variance Efficiency and Arbitrage Pricing', Journal of Business, Vol. 60, pp.97-112 
Grinblatt, M. and Titman, S. (1994). 'A study of monthly mutual fund returns and performance evaluation techniques', Journal of Financial \& Quantitative Analysis, Vol. 29, pp.419-444

Grinblatt, M. and Titman, S. and Wermers, R. (1995). 'Momentum Investment Strategies Portfolio Performance and Herding: A Study of Mutual Fund Behavior', American Economic Review, Vol. 85, pp.1088-1105.

Itzhak Ben-David, Francesco Franzoni and RabihMoussawi (2012). 'Hedge fund stock trading in the financial crisis of 2007-2009', The Review of Financial Studies, Vol. 25, No. 1, pp. 1-54.

Jensen, Michael C. (1968). 'The Performance of Mutual Funds in the Period 1945-1964', Journal of Finance, Vol. 23, pp. 389-416.

Koenker R., Gilbert Bassett (1978)." Regression Quantiles"Econometrica, Vol. 46, No. 1, pp. 33-50

Roll, Richard. (1978). 'Ambiguity When Performance Is Measured by the Securities Market Line, Journal of Finance, Vol. 33. pp. 1051-1069.

Roll, Richard. (1981). 'Performance Evaluation and Benchmark Error II', Journal of Portfolio Management, Vol. pp. 17-22.

David Ruppert. (2004). 'Statistics and Finance: An Introduction', Springer Texts in Statistics, Springer-Verlag New York.

Sharpe, W. (1966) 'Mutual Fund Performance', Journal of Business, Vol. 39, pp. 119-138.

Sharpe, William F. (2007). 'Expected Utility Asset Allocation', Financial Analysts Journal, Vol. 63, pp. 18-30.

Treynor, Jack L. (1965). 'How to Rate Management of Investment Funds', Harvard Business Review, Vol. 43, pp. 63-75.

Javier, Rodriguez (2018). 'An Empirical Study of Regional Mutual Funds' Diversification Value', Applied Finance Letters, Vol. 7 Nol, pp. 22-31.

Bruce A. Costa, Keith Jakob, Scott J. Niblock \& Elisabeth Sinnewe (2014). 'Australian Stock Indexes and the Four-Factor Model', Applied Finance Letters, Vol. 3 Nol, pp. 10-21

Sundar, Sankaran (2018). 'Indian mutual funds handbook: A guide for industry professionals and intelligent investors', Vision Books 2018.

Background Mutual fund industry in India Retrieved November 30, 2019, from https://www.amfiindia.com/research-information/mf-history

Russ Wermers (2002). 'Mutual Fund Performance: An Empirical Decomposition into Stock Picking Talent, Style, Transactions Costs, and Expenses', Journal of Finance, 55 (4) (2000), pp. 1655-1695

D. Bams and R. Otten (2002). 'European mutual fund performance', European Financial Management, 8 (2002), pp. 75-101

Chen, Joseph, Harrison Hong, Ming Huang, and Jeffrey Kubik, (2004). 'Does fund size erode mutual fund performance?' American Economic Review, 94: 1276-1302.

Ferreira, Miguel A., AneelKeswani, Antonio F. Miguel, and Sofia Ramos, 2013, 'The determinants of mutual fund performance: A cross-country study', Review of Finance 17, 483-525. 


\section{Appendix A}

Table A1: Details of the fund houses and the number of schemes in each fund house

\begin{tabular}{lrr}
\hline Mutual fund house & Number of schemes analysed & Percentage \\
\hline BARODAPIONEER & 5 & 0.67 \\
CANARAREBECO & 21 & 2.82 \\
EDELWISES & 20 & 2.69 \\
ESCORTS & 10 & 1.34 \\
IDBI & 13 & 1.75 \\
AXIS & 5 & 0.67 \\
DSP & 46 & 6.18 \\
FRANKLIN & 20 & 2.69 \\
HDFC & 49 & 6.59 \\
HSBC & 24 & 3.23 \\
ICICI & 24 & 11.02 \\
IDFC & 82 & 5.51 \\
INDIABULLS & 41 & 0.4 \\
INVESCO & 3 & 3.23 \\
JM & 3.08 \\
JPMORGAN & 24 & 1.08 \\
KOTAK & 8 & 1.88 \\
LIC & 14 & 1.34 \\
LT & 10 & 3.36 \\
MIRAE & 25 & 3.36 \\
MOTILAL & 1.08 \\
PEERLESS & 25 & 0.81 \\
PRINCIPAL & 8 & 0.81 \\
RELIANCE & 3.36 \\
SAHARA & 6 & 8.74 \\
SBI & 6.45 \\
Total & 6 & 10.22 \\
\hline
\end{tabular}

The table reports the number of Asset Management Companies and the scheme analysed data which consists of 744 mutual fund schemes across 26 Asset Management Companies (AMC's)

Figure 1.

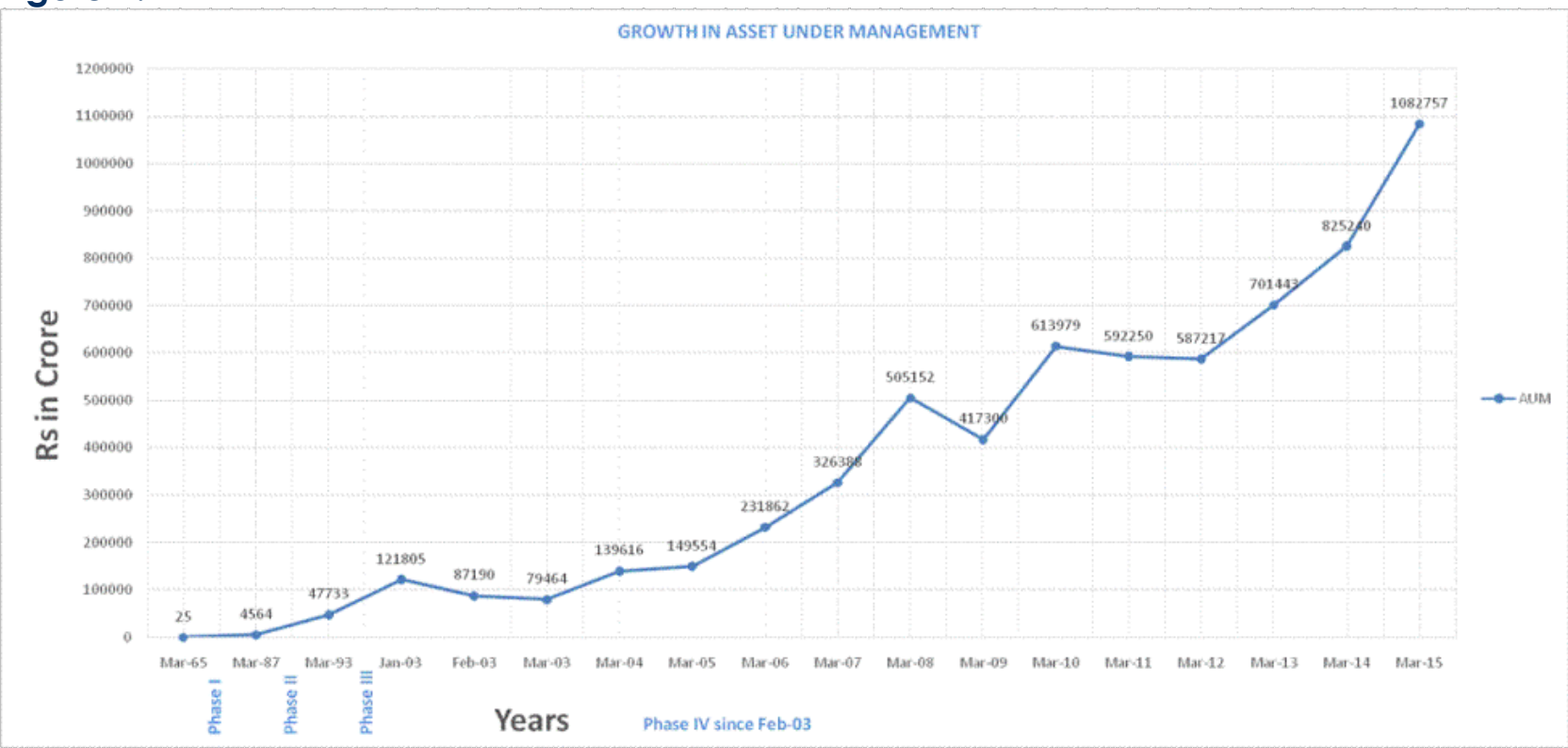

Source: AMFI website https://www.amfiindia.com/research-information/mf-history

The recession period during 2008-2010, overall, we have seen an increase in the AUM. Although the AUM declined during the subprime crisis at the initial year for the period 2008-09 but had increased subsequently for the period 2009-10 


\section{Appendix B: Background and Phases of the Mutual Fund Industry in India}

There were 4 phases in the growth of the Indian mutual fund industry. First Phase - 1964-1987 whereby the end of 1988 UTI had Rs. 6,700 crores of assets under management (AUM). Second Phase - 19871993 (Entry of Public Sector Funds) where many public sector firms entered such as LIC, GIC,SBI Mutual Fund which was the first non-UTI Mutual Fund established in June 1987 followed by Can-bank Mutual Fund (Dec 87), At the end of 1993, the mutual fund industry had AUM of Rs. 47,004 crores which are rapid growth. Third Phase - 1993-2003 (Entry of Private Sector Funds) 1993 was the year in which the first Mutual Fund Regulations came into existence, under which all mutual funds, except UTI which needed to be registered and governed. The Kothari Pioneer (now merged with Franklin Templeton) was the first private sector mutual fund registered in July 1993. By the end of January 2003, there were 33 mutual funds with total assets of Rs. 1, 21, 805 crores. The Unit Trust of India with Rs. 44,541 crores of AUM were ahead of other mutual funds. Fourth Phase - since February 2003; In February 2003, due to the repeal of the Unit Trust of India Act, 1963 UTI was bifurcated into two separate entities. The MF Industry's AUM has grown from Rs.10.96 trillion as on October 31, 2014, to Rs.26.33 trillion as on October 31,2019 , about two and a half times increase in 5 years.

\section{Appendix C: Histogram of PCMs}

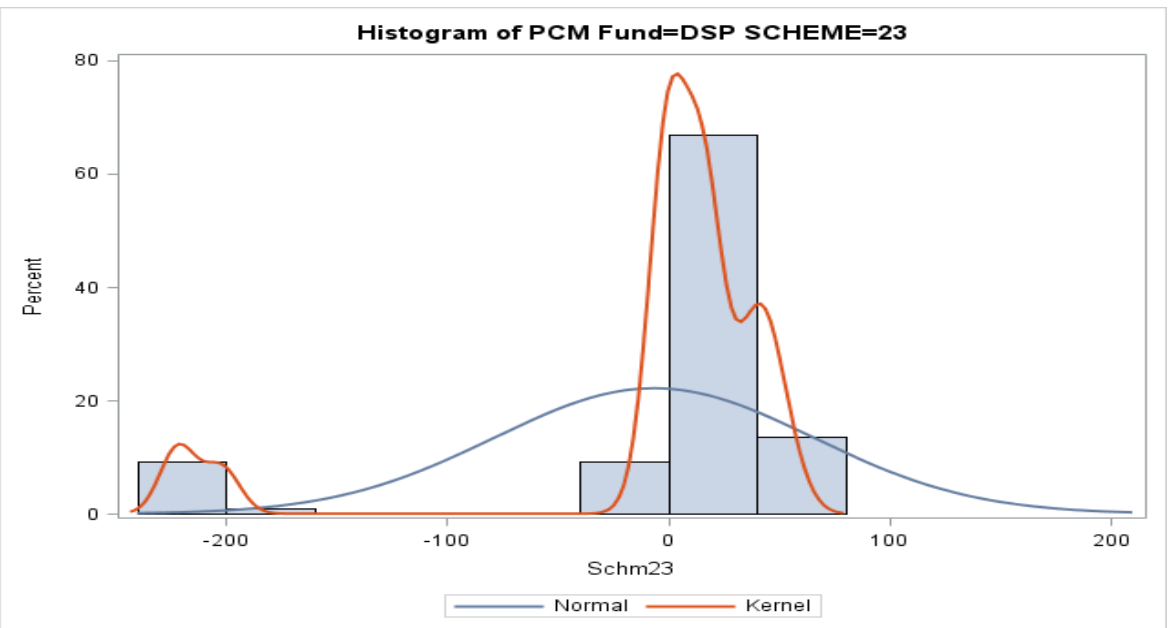

The graph shows the histogram for the PCM for the fund for a particular scheme.

The graph shows that the distribution is highly skewed and away from normal.

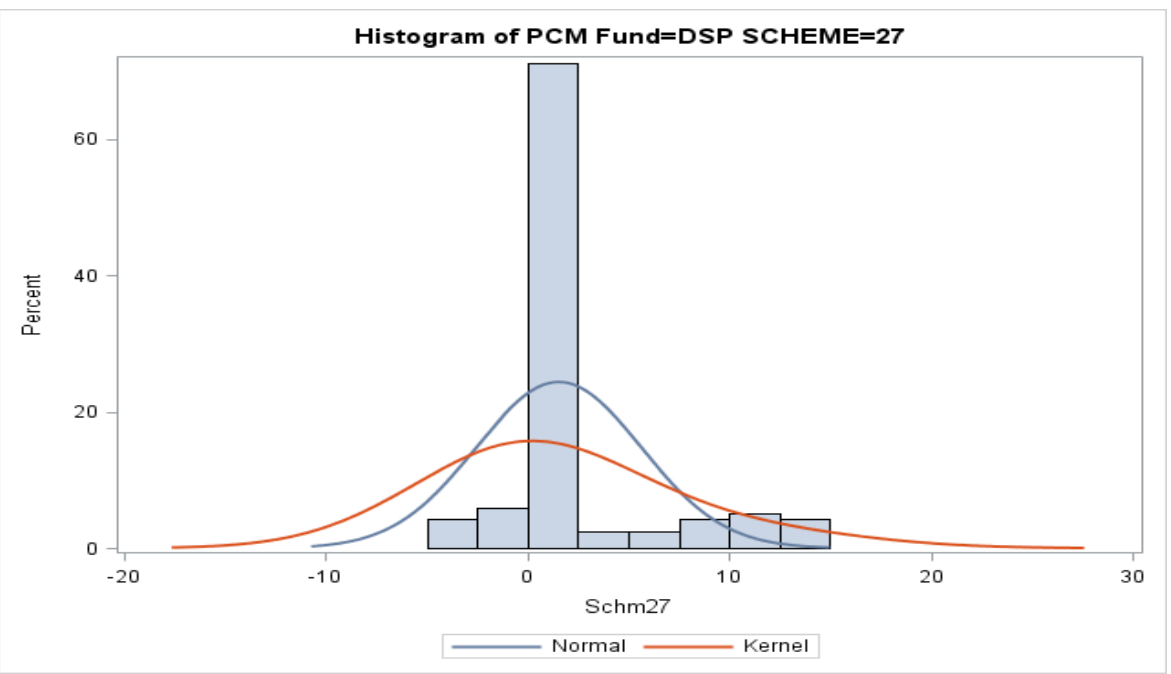

The graph shows the histogram for the PCM for the fund for a particular scheme. The graph shows that the distribution is highly skewed and away from normal. 


\section{Appendix D: Types and Categories Mutual Fund Industry in India ${ }^{22}$ :}

There exist several ways to classify mutual funds:

The first could be based on functional classification. i.e. 1) Open Ended scheme and 2) Closedended scheme.

Mutual funds can also be classified based on portfolio, i.e. 1) Income funds 2) Growth fund and, 3) Balanced Funds.

They can also be classified based on investment objective, i.e. 1) Equity fund 2) Debt fund and, 3) Hybrid fund.

In our study, we have analysed Open-Ended equity schemes which predominantly belong to Income and growth funds. For the regression, the ownership and AMC structure classifications were done were classified as per the AMFI website into three types based on sponsorships.

1) Type_1 Bank sponsored, e.g. Canara Robeco Asset Management Co. Ltd,

2) Type_2 Institution, e.g. LIC Mutual fund Asset Management Co. Ltd.

3) Type_3 Private, e.g. Sahara Asset Management Co. private limited.

Also based on ownership structures of the AMC, the following categories were formed:

1) Category 1 for Foreign-owned AMCs, e.g. Franklin Templeton Asset Management (India) Private Ltd.

2) Category 2 for Indian owned AMCs, e.g. L\&T Investment Management Ltd.,

3) Category 3 for Joint venture is predominantly Foreign, e.g. HSBC Asset Management India Private Ltd.

4) Category 4 for Joint venture predominantly Indian, e.g. Axis Asset Management Company Ltd.

5) Category 5 for all the others.

Source: https://www.amfiindia.com/

22 This section is based on Sankaran (2018), Handbook of Mutual Fund Distributors by AMFI and Pathak (2011) 